\title{
When You, the Doctor, are the Scientist
}

\author{
Murray Grossan* \\ Graduation 1948 University of Georgia School of Medicine, USA
}

Submission: April 23, 2017; Published: April 28, 2017

*Corresponding author: Murray Grossan, Graduation 1948 University of Georgia School of Medicine, 8631 W 3rd St. Ste 440 East Los Angeles, Ca 90048, USA, Tel: 310659 1006; Email: drgrossan@yahoo.com

\section{Editorial}

Last week a drug representative visited and left samples of their latest wonder nasal spray, complete with colorful graphs and testimonials of smiling people with amazing beautiful teeth.

How can you tell if this new product is actually better than what you currently recommend, which also happens to cost much less?

Answer: you be the scientist.

Agreed, you can't do the multimillion dollar tests with double blind factors that Food and Drug agencies require. But, you can gauge yourself whether method A is best for your patient.

\section{Method}

It only takes a few minutes to have your patient fill out the SNOT 22 questionnaires. This can establish if the degree to which the patient is having sino-nasal symptoms. Then, after your therapy, have the patient fill this out again. It is surprising that with only a very small number of such tests, you end up with a recognized evaluation that can answer whether this method is worth continuing or not. Or you can set your own measurement of symptoms. In every hospital there is a chart on the wall: How much pain do you have today? The measurements go from 1 to 10 . This indicates to the doctor and nurse, if the patient symptoms are improving or not [1-4].

A useful method is to measure mucociliary clearance, using the Saccharine Test. Here a particle of Saccharine is placed on the medial surface of the inferior turbinate, one $\mathrm{cm}$ behind the anterior surface. The patient site quietly and reports when the sweet saccharine is tasted. She is asked to swallow every 30 seconds. When she tasted the saccharine, this means it has traveled through the nose and down to the tongue. Normal time is 5 to 8 minutes.

The saccharine test has established diagnostic standards:
a) 1-4 minutes Acute Allergy
b) 5-7 " Normal MCC
c) $9-15$
Infection
d) 16-28 " Chronic Infection
e) $30+\quad$ Irreversible poor MCC

This test can be repeated after therapy and is independent of subjective reports by the patient. Best of all, you don't need a Research Grant to perform this in your office!

\section{Why This Is Important}

In 1976 I reported on the use of EMG biofeedback for the treatment of tinnitus. At that time I reported on identifying the tinnitus by matching it to the audiometer sounds, as well as measuring the volume. This means of measurement guides the therapy of tinnitus. If the tinnitus tone shifts, or reduces, these are excellent indications to guide your therapy. You can see how important a simple measurement can be in determining the science of therapy. For tinnitus, there are excellent tests such as the Tinnitus Functional Index, or The Tinnitus Severity Index, that can be used as a guide for your therapy, and add science to your findings. The number of depression and similar indexes are also available. You may prefer measurements of fever or the number of pain pills taken for a condition. For example, Migraine headaches are classified by the frequency of pain medication. A Nobel Prize awaits anyone who develops a better means of measuring cancer [5].

\section{Benefits}

Doctors are issued protocols of treatments. Very scientific papers recommend precise dosage and therapies for many illnesses. This may restrict your own innovation and creativity. For example, when I developed pulsed nasal/sinus irrigation (the Hydro Pulse ${ }^{\mathrm{TM}}$ ), the fact that I could use before and after Snot 22 measures and Saccharine Test Times, made it possible to confirm the advantages of this form of therapy. I propose that being able to apply science to your creativity; will further unleash your ideas that can better aid your patients. As a doctor, trained in science, there is no reason why your insight and experience is less important than the researcher in the ivory tower. 


\section{Conclusion}

It would be gratifying if every time you find your own particular therapy to be effective, you could obtain the multimillion dollar grant to perform the giant studies. However, your own observations are valid and noteworthy. Finding a method of measurement - whether it is a SNOT 22, a Saccharine Test or one of the myriad of questionnaires used in some studies; by performing these measurements, you are the scientist and your patients and peers appreciate that.

\section{References}

1. Farhood Z, Schlosser RJ, Pearse ME, Storck KA, Nguyen SA, et al. (2016) Twenty-two-item Sino-Nasal Outcome Test in a control population: a cross-sectional study and systematic review. Int Forum Allergy Rhinol 6(3): 271-277.

2. Grossan M (1976) Treatment of Subjective Tinnitus with Biofeedback. Ear Nose Throat J 55(10): 314-314.

3. Grossan M (1975) A Brief Introduction to Biofeedback for Otolaryngologists. ORL Digest.

4. Kennedy JL, Hubbard MA, Huyett P, Patrie JT, Borish L, et al. (2013) Sino-nasal Outcome Test (SNOT-22): A predictor of post-surgical improvement in patients with chronic sinusitis. Ann Allergy Asthma Immunol 111(4): 246-251.

5. Levy JM, Mace JC, Rudmik L, Soler ZM, Smith TL (2017) Low 22-item sinonasal outcome test scores in chronic rhinosinusitis: Why do patients seek treatment? Laryngoscope 127(1): 22-28.

\section{Your next submission with Juniper Publishers} will reach you the below assets

- Quality Editorial service

- Swift Peer Review

- Reprints availability

- E-prints Service

- Manuscript Podcast for convenient understanding

- Global attainment for your research

- Manuscript accessibility in different formats

( Pdf, E-pub, Full Text, Audio)

- Unceasing customer service

Track the below URL for one-step submission https://juniperpublishers.com/online-submission.php 